\title{
Mission Objective: \\ Carry the White Man's Burden to Outer Space - The Gamification of Colonization in Dead Space
}

\begin{abstract}
Survival horror video games were recognized in the late nineteen-nineties for their cumbersome gameplay determined by complicated controls and inefficient core mechanics. After 2005, survival horror games started to move away from their traditional game design and to show more openness to the dominant game design norms of the action genre. The new survival horror games sought to eliminate the hypermedial elements that had characterized their predecessors and offer gamers an immersive gameplay experience similar to that of $\mathrm{AAA}^{1}$ action games. In this article I look at the survival horror game Dead Space $(E A, 2008)$ and analyse the way in which the game naturalizes its ludic functions in order to strengthen the illusion of immersion and how the illusion of immersion strengthens the ideology of white supremacy embedded in the remediated colonial discourse of the game. In keeping with Jesper Juul's approach ("On Absent Carrot Sticks") to the relation between the game's fiction and the game's rules, I show that in the case of Dead Space traditionally antimimetic elements of video games such as the heads-up display are implemented into the fictional text-actual-world. As a result, conventionally extradiegetic game mechanics such as the inventory now become intradiegetic elements that no longer draw the player away from the storyworld. ${ }^{2}$ The realism of the storyworld works in favour of a naturalization of the colonial tropes that the video game remediates.
\end{abstract}

Keywords: survival horror; colonialism; science fiction; naturalization.

\section{Andrei NAE, $\mathrm{PhD}$}

University of Bucharest

andrei.nae@lls.unibuc.ro

andreivnae@gmail.com

EKPHRASIS, 2/2018

Cinema, Cognition and Art pp. 157-167

DOI:10.24193/ekphrasis.20.9 Published First Online: 2018/11/20
Video games are a hybrid medium marked by a tension between their challenge-based ludic nature, and the growing importance that the gaming industry has been showing in the past twenty years for the narrative potential of video games. Despite the position of some scholars in the field of game studies who see narrative as a mere ornament of gameplay (Eskelinen "The Gaming Situation"), more 
recent games have started to foreground the narrative function of some game mechanics. This trend was popularized by survival horror video games in the late nineteen-nineties was soon taken up by the entire AAA gaming industry. In this article, I look at the video game Dead Space (EA Redwood Studios, 2008) and analyse the gamification of the narrative content characteristic of the action science fiction cinematic genre. In order to achieve this goal, I will first look at the game's intermedial generic context and analyse how the cinematic conventions of the scifi and of the action genre feed into the game's storyworld and, eventually, into its gameplay. In addition to this, I also inspect the game in its intramedial context to see how the game relates to the well-established tradition of sci-fi shooting games. After looking at the broader generic backdrop, I investigate the storyworld proper and look into the manner in which the game's formal aspects are explained and accounted for by the storyworld, or, to use the words of Jesper Juul, how the rules are implemented into the game's fiction (175). Lastly, I focus on the manner in which the ideology of space science fiction films is adapted to the medium of video games.

\section{Intermedial Generic Context: Gamifying Narrative Action Science Fiction Films}

Ever since their inception, video games have had to rely on familiar aural and visual representation in order to make their challenges intelligible. In order to do so, video games have been engaged in a process of remediation whereby they incorporate and imitate the representational affordances of other media. The medium which video games have been most keen on remediating is the feature film. Even in its most abstract stages, video games have relied on cinematic references in order to give substance to their worlds (Wolf 51). One of the earliest video games, Spacewar! (Russel, 1962), pays tribute to the science fiction genre by simulating a space battle between the player's avatar represented on-screen by a space ship and a series of combatants. Some games go even further and present themselves as procedural adaptations of feature films, as it is the case with E.T. Extra-Terrestrial (Atari, 1982), or Halloween (Wizard Video, 1983).

The connection between the two media has turned out to be long-lasting, fruitful one. On the one hand, video games have mirrored the trends of cinema both in terms of form, and in terms of content, while, on the other hand, cinema has responded by adapting video games into feature films. Max Payne, Silent Hill, or Hitman are only some of the video game franchise that have been adapted into feature length films that provide a linear representation of the action simulation of the games. Moreover, films and video games, along with other media as well, have been used separately to represent various parts of one consistent transmedia storyworld. This type of practice involving video games rose to prominence around the turn of the millennia with franchises such as the Matrix whose stories are deployed across multiple media, including video games (Ryan "Transmedial Storytelling and Transfictionality" 363). 
It is in this broader intermedial context that the storyworld of Dead Space has to be construed. The protagonist of Dead Space is Isaac Clarke, who is an engineer aboard a space ship called the Kellion. In 2508, the Kellion receives a distress signal from a fellow starship that was involved in a mining operation on the planet Aegis VII. The crew decide to head for Aegis VII and aid the fellow starship, but are unable to dock the Kellion properly and eventually crash. Upon their arrival, they are attacked by vicious human-like monsters called necromorphs. As the player struggles to repair the Kellion, she learns that the monster are, in fact, former crew members who had been infected by a virus coming from an ancient religious artefact found during the mining process on the Aegis VII. The player attempts to get the artefact off the station, however, in a hollywoodian twist of the plot, a fellow crew member, Kendra Daniels, sabotages Isaac's endeavour and takes the artefact back to the station. It turns out that the artefact was an artificially made replica of the original one found on Earth and that it had been purposefully placed on the Aegis VII so that the government could assess the effect that the artefact had on humans. Once the artefact is retrieved by Kendra, the Hive Mind, the leading necromorph, awakens and has to be defeated by Isaac Clarke. After the Hive Mind is killed, Isaac escapes on a shuttle.

The story of by Dead Space pays tribute to the action space science fiction genre that is well established in the cinema. While films such as 2001: A Space Odyssey (Kubrick, 1968), or Alien (Scott, 1979) had popularized the major themes of space science fiction such as isolation, the corruption and ruthlessness and power structures (governments and corporations), and the colonization of space, it was not until the release of Aliens (Cameron, 1986) that such themes had been combined with the spectacle of action films, thus leading to a hybrid genre - the action space science fiction film. This hybridity made the new genre compatible with action video games that were also marked by a tension of their own.

As several scholars have pointed out (Jenkins "Game Design as Narrative Architecture"; Ryan Avatars of Story 13), video games do not only represent stories, they also simulate them Although game engines also play back pre-rendered cutscenes, audio files, or show texts or pictures, for throughout much of the games, they provide the rules that govern the interactive loop between the player and the game world. Like actors, players enact roles within the confines of the game designs, which leads to the emergence of stories When the hybrid genre of action science fiction transcended its cinematic medium and moved to video games, the science fiction elements were more prone to be adapted linearly by the game's scripted and embedded narrative, while the action spectacle lent itself more easily to procedural adaptation and, therefore, was at the heart of the game's simulation.

These aspects of gamifying action science fiction are well represented in Dead Space. The linear sequence of events that lead to Isaac Clarke's escape from Aegis VII, the backdrop of the game's action sequences, the characters and the motives behind their actions are all represented via non-interactive cut-scenes, analog or digital documents 
(scattered around the game world for the player to collect) and plot bottlenecks (Egenfeldt et al. 181) through which each player must pass in order to make progress in the game. On the other hand, the action spectacle is procedurally rendered in the game's simulation. The player must battle various types of necromorphs by employing a series of weapons which she herself chooses and modifies. Combat is governed by a set of rules that establish how each gun works, how many hitpoints it can deduct from the enemy's health, or what the enemies' weak spots are.

\section{Intramedial Generic Context:}

\section{Dead Space's relation to the History of Gamifying Action Science Fiction Cinema}

Dead Space is by no means the first game to gamify the cinematic genre of action science fiction. Quite on the contrary, this type of gamification has a long tradition that runs parallel to the modern $3 \mathrm{D}$ shooting games that emerged in the early nineteennineties and even earlier shooting games that embraced forms such as side-scrolling and run-and-gun. Early games such as Konami's Contra series, the canonical first person shooter series, Doom and Quake, along with games such as Half-Life (Valve, 1998), System Shock 2 (Irrational Games, 1999), or Prey (Human Head Studios, 2006) simulate the struggle of singular, isolated protagonists facing an alien invasion either on earth or on a derelict space station. In its evolution from the late eighteen-eighties and early nineteen-nineties to 2008, Dead Space's year of release, these science fiction action games have consistently increased the complexity of their storyworlds. While in the case of early games the narrative information was restricted to one page in the game manual or a brief cut-scene, with each new release more and more stress has been laid on the games' narrativity to the point that ludic functions have ended bearing a narrative function as well.

Although Dead Space features the high degree of narrativity that had become a hallmark of the genre around the time of its release, formally Dead Space differs from the aforementioned examples. Most of the games listed above are first person shooters, which means that we are dealing with a set of games whose mechanics empower the player and enable her to effectively dispose of her adversaries. This empowerment is buttressed on the symbiotic control ${ }^{3}$ of the first person perspective afforded by the mouse, in the case of PC gaming, the analog stick in the case of console controllers, or, more recently, the movement of the head when using virtual reality gear such as the system provided by the PlayStation VR. Empowerment is also based on the playable character's ability to shoot while running and jumping, as well as a general fluidity of gameplay. In addition to this, the playable character can carry an infinite amount of ammunition and game relevant items that aid her in her confrontation with her assailants.

Unlike first person shooters, Dead Space is not as gamer-friendly. The game employs a rigid third person view in the vein of Resident Evil 4 (Capcom, 2005) that enfeebles, rather than empower the player. Dead Space uses a tracking camera that 
follows the playable character as he moves in the game world. In order to shoot, the player must press and hold an aiming button that immobilizes the playable character and moves the camera to a closer shot in an over-the-shoulder position. This way, when shooting, the playable character is vulnerable to attacks coming from enemies outside the frame of the camera. The simulation of combat is also encumbered by the game's item management system. The playable character can carry only four weapons at a time, and has to regularly browse his inventory for items and ammunition, this way fragmenting gameplay and making combat more difficult.

The game design of Dead Space brings the game closer to one particular strand of the action genre, namely the survival horror. As Bernard Perron points out, games like Alone in the Dark (Infogrames, 1992) and Resident Evil (Capcom, 1996) approached the action genre from a new perspective. By featuring different fixed camera angles for different locations, tank controls, inefficient combat mechanics, little ammunition, and game pausing inventories, these games managed to simulate the helplessness of the playable character. Resident Evil 4 marks a break from the traditional survival horror formula and introduces a new set of game design norms that bring the survival horror closer to the prototypical action shooting game. In a manner similar to Resident Evil 4, Dead Space negotiates between survival horror's emphasis on the playable character's helplessness and action games' empowering of the playable character. The aforementioned formal traits of the game do, indeed, render the playable character less capable of defeating his foes in comparison to similar player avatars in first person shooters or more conventional third person shooters, but, on the other hand, the simulation of combat afforded by Dead Space is nowhere near the vulnerability which characterizes the simulation of combat in games such as Silent Hill (Konami, 1999), or Forbidden Siren (Sony, 2003). However, what Dead Space does share with these last two games and other classical survival horror games is the fact that these gameplay encumbering mechanics also have a narrative function.

\section{The Narrative Function of Game Mechanics in Dead Space}

Although not in favour of regarding video games as narratives, Juul maintains that the game's fiction is an important part of the gameplay experience. Juul sustains that the fiction's relation to game mechanics is of three types:

1. Fiction implemented in rules: The most straightforward situation, where the game rules are motivated by the game's fiction. [...]

2. Fiction not implemented in game rules: When fiction suggests a possibility that is not accessible to players. [...]

3. Rules not explained by fiction: When rules are difficult to explain by referring to the game's fiction (175).

The types of relation entertained by fiction and game mechanics are generally present in various proportions in all video games. For example, in a more conventional third person shooter such as Max Payne (Remedy Entertainment, 2001), the visual 
representation of the game world cues players to infer a series of in-game action that are afforded by the game mechanics. The fact that Max carries a gun allows players to infer that the gun can be used to shoot assailants in the game world. This expectation is soon confirmed by the game which uses shooting mechanics to simulate armed combat (fiction implemented in rules). On the other hand, not all the possible actions inferred by the player can be performed by the playable character. While the gun can be used for shooting, its pat cannot be used to hit the adversaries, neither can it be used for other actions. In this case, the game's fiction, or, as Ryan calls it, the storyworld's static component, is not implement in the game's rules. Finally, Max Payne features some game mechanics that cannot be accounted for by the game's fiction. The most relevant case is that of the bullet time, a mechanic that slows down time, making it easier for the player to react the actions of the adversaries. This rule is neither explicitly nor implicitly accounted for by the fiction. The storyworld of Max Payne is a verisimilar one that would normally preclude such a possibility, but there is no diegetic element (an aspect of Max' biography, a line of dialogue, etc.) that integrates this mechanic into the game's narrative.

As a representative of survival horror, Dead Space is a video game that attempts to implement its fiction into rules to a greater extent than more conventional mainstream action games. One hallmark game design element of traditional survival horror video games is the inventory. In games such as Resident Evil, the player inspects relevant ludic information by accessing a new screen that pauses time in the game world. Unlike the realism of the game's simulation, these inventories are hypermedial in the sense that they employ the graphic design and functionality of a menu: simple geometric forms and functions that the player has to select and activate by manipulating the buttons on the D-pact on the PlayStation controller, or the arrow keys on the PC keyboard. This important core mechanic of traditional survival horror video games is not explained by the storyworlds of the games and, therefore, decreases the realism of the gameplay experience and affect the games' capacity to immerse the player. On the other hand, the inventory allowed traditional survival horror video games to use no heads-up display, therefore making the visual representation of the simulation more cinematic and more immersive.

Dead Space presents both features (an inventory mechanic and no heads-up display), but lack the disadvantage of hypermediacy caused by the inventory in other survival horror games. In Dead Space, all ludic information pertaining to health, oxygen, as well as the power level of the playable character's special abilities, are graphically represented on the playable character's suit. This implies that the ludic information is no longer an extradiegetic element that overlays the visual representation of the game world, but rather the ludic information is part of the storyworld per se, or, to use the term coined by Marie-Laure Ryan, the text-actual-world. This applies to ammunition, too, which is numerically rendered on the playable character's gun. A similar strategy of narrativization is used with respect to the inventory. Instead of pausing game time 
and accessing an extradiegetic screen, in Dead Space the inventory is a projection of the playable character's suit (see Figure 1). This projection is, once again, part of the text-actual-world which emerges through gameplay. Activating the inventory does not draw players away from the storyworld of the video game, but rather keeps them immersed in the virtual storyworld of the game. In opposition to the hypermediacy that characterizes the inventory in traditional survival horror video games, Dead Space narrativizes the inventory so as to maintain the illusion of medium transparency.

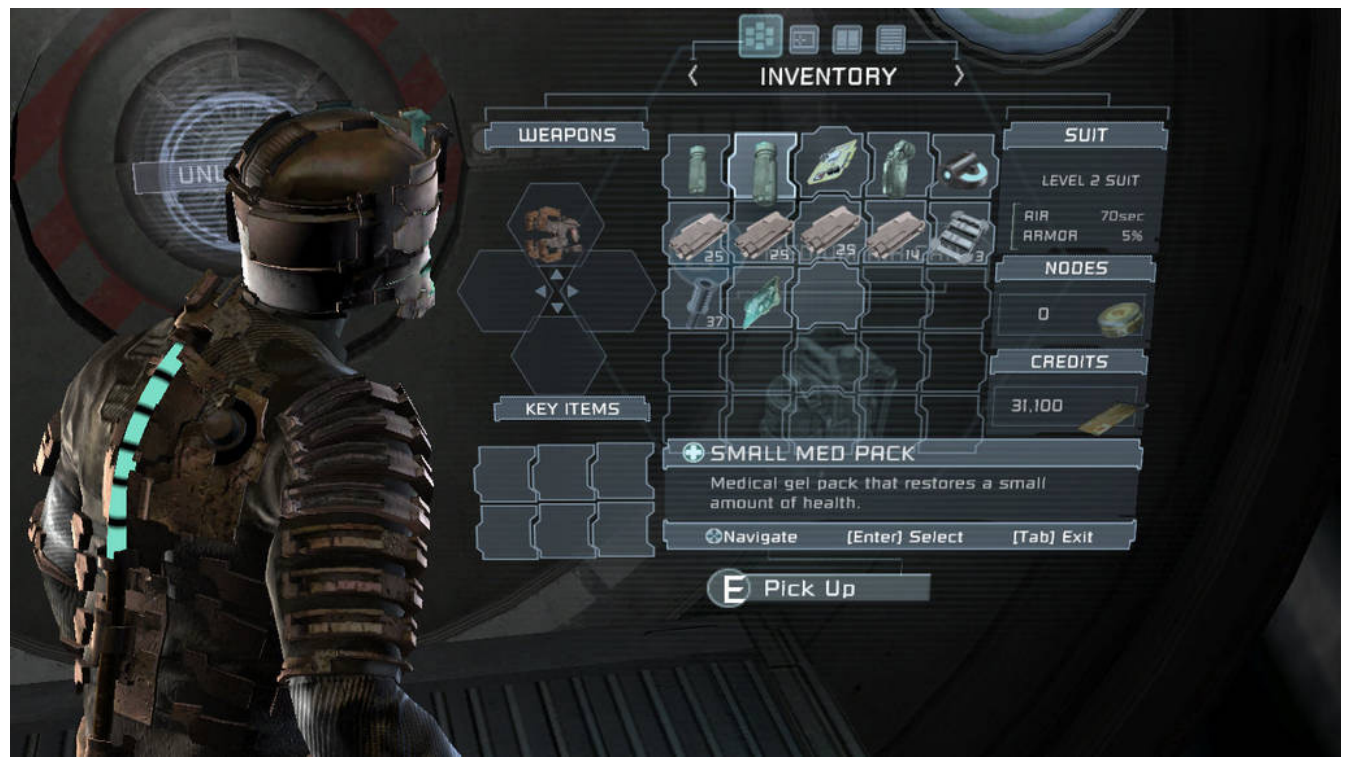

Figure 1

The Remediation of Colonialism

As already pointed out, the history of video games can be seen as a history of remediation. Video games have evinced a strong propensity to cannibalize already established media in order to augment their level of immediacy. However, this technological remediation is also one of a cultural nature. As Astrid Erll and Ann Rigney show, cultural representations of the past travel across media under conditions similar to that of the representational affordances of media. The specific means of representation of media play an active role on shaping the representations of the past and, consequently, our cultural memory of it (Erll et al. 1). In this section I look into the manner in which Dead Space represents and simulates a triumphant version of modern colonialism by highlighting the bearing that the video games' medium specificity has on the cultural memory of colonialism.

The emergence of the Enlightenment brought along the idea of the civilizing mission, i.e. the western world considered that it was its duty to spread its civilizational model to the 'backward' regions of the world. This added an important 
cultural dimension to the already existing practice of economic colonization that preceded modernity. Although the civilizing mission had a dominant status in the modern western world, there was also no shortage of criticism in various forms across multiple media. A good example in this respect might be considered Joseph Conrad's canonical work, Heart of Darkness, which stressed how the civilizing mission was a hypocritical alibi for the exploitation of natives (Ashcroft et al. 20). However, it was not until the end of the Second World War that the dominant discourse on colonialism underwent a radical shift from triumphant optimism to that of blame and condemnation.

Despite this new derogatory view, colonial discourse did not cease to exist, but rather adapted itself to the new age, namely the cold war and the space race. Instead of relinquishing the idea of colonialism, the modern world of the cold war turned its focus away from the 'uncivilized' parts of the world and redirected it to outer space. This new preoccupation for colonizing the cosmos inevitably marked the science fiction genre in film and other media on both sides of the Iron Curtain. This led to an abundance of films that thematise space travelling and the challenges that come along with it (see films such as Alien (Scott, 1979) or Solaris (Tarkovsky, 1972)). These films recuperate the main tropes of colonial discourse, such as the civilizing mission, metaphors of light in opposition to metaphors of darkness, a romantic view on nature as restless and unruly, and the civilizational conflict between the modern white rational man and the pre-modern communal other, who is now not a person of different skin colour, but a different species. The gamification of this cinematic genre that rose to prominence in the second half of the twentieth century led to a remediation of colonialism along the same aesthetic and ideological lines as those of the feature films. As I show in the next paragraphs, although featuring a critique of institutional forms of authority that is often present in science fiction films that tackle the issue of colonizing space, Dead Space pays tribute to above listed tropes of colonial discourse.

As already pointed out, the game is centred on the conflict between Isaac Clarke, an engineer, and the Marker, an apparently ancient artefact that turned the members of the space station Ishimura into Necromorphs, who are irrational mutants driven by basic urges. The two sides of the conflict represent, in fact, a civilizational conflict between the rational enlightened white male and the irrational forms the otherness, whom the former must subdue with the help of artificial means. In order to represent this conflict, Dead Space often falls back on the antithesis between light and darkness. Throughout the game, the simulation amounts to the player repairing various segments of the Ishimura, which implies a progressive lighting up of the station. His identity as an engineer enables Isaac Clarke to employ his reason in repairing the damages caused by the forms of otherness and dispelling the darkness that had engulfed the station.

The necromorphs, too, can be considered a remediation of the colonial anxiety of going native, i.e. the fear that westerners living among natives will eventually 
be 'contaminated' by pre-modernity (Ashcroft et al. 106). The crew of the Ishimura are unable to resist the influence of the marker and are turned into hybrid entities that present both human and non-human features. However, it must be noted that the fear of going native is updated in Dead Space to new ideological coordinates. The racism that pervaded modern western culture is a taboo to our contemporary postmodern world. As a result, rather than assimilating elements of the cultural identity of different ethnic groups, the crew of the Ishimura incorporate traits of a different species. This aspect moves the cultural anxiety of going native away from its original racism and refashions it in accordance with speciesism.

The crew's yielding to the influence of the Marker is connected to another modern anxiety, namely that of religious bigotry. In the seminal modern text "Beantwortung der Frage: Was ist Aufklärung?“, Immanuel Kant urges his contemporaries to dare to rely on their own intellects and to resist retrograde forms of authority such as the church (7). The video game maintains the modern scepticism with respect to submitting oneself to religious authority. In Dead Space, the captain of the Ishimura is a strong believer in the doctrine of Unitology, a religious denomination that claims that mankind was created by an alien race and that salvation implies the reunion of mankind and the race of their creators. His religious bigotry compels him to abandon the initial mining mission in order to search for the artefact, instead. Religious bigotry, therefore, constitutes the plot's inciting moment that breaks the equilibrium of the storyworld. The underlying premise of the game's critique of religious bigotry seems to be that the failure of colonialism lies not within colonialism itself, but rather in the failure of the heralds of modernity to live up to their own standards. In Dead Space, the colonization of space is a functional project until religion interferes with the mission and derails the Ishimura from its initial purpose. Had the crew members resisted religious influence, the dramatic events of Dead Space would never have happened. Therefore, what could have been a critique of colonialism ends up reinforcing the universality of modern thought and the civilizing mission.

Another colonial trope often encountered is Dead Space is the high romantic view on nature. Only this time, the untamed dark thick donning woods of the jungle are replaced with the inhospitable outer space. In a manner similar to the jungles of Africa, the cosmos of Dead Space is represented as grandiose and majestic, but also dangerous, with the exception that Dead Space uses ludic and cinematic rather than the literary or pictorial means that $19^{\text {th }}$ century artists had at their disposal. In the game the player must sometimes leave the confines of the Ishimura and travel through the cosmos. During these parts of the game, the player must quickly find oxygen packs, manage the zero gravity movement mechanics, and swerve through asteroid showers.

Finally, Isaac Clarke's triumph over the necromorphs reasserts the superiority of western culture over premodernity and nature. In a manner similar to its cinematic generic counterparts, Dead Space uses its specific means to create the illusion of 
realism and, consequently, make its ideology implicit. While films use technique such as continuity editing and synchronization, in the game the white supremacy underlying colonial discourse buttressed on the realism of the game's storyworld which is also reinforced by the narrativization of the game mechanics that govern the player's control over the playable character.

\section{Conclusion}

The survival horror game Dead Space is a representative of a well-established action game tradition that gamifies science fiction cinema. In keeping with the narrativenumber structure of mainstream films, Dead Space tends to use its linear means of representation in order to render the science fiction elements of the storyworld, while using its interactivity to simulate the action numbers characteristic of action films. The rules/game mechanics that afford the simulation are, nevertheless, to a great extent explained by the storyworld of the game, thus ensuring a high degree of realism. This leads to a naturalization of social hierarchies implicit in colonial discourse. Dead Space remediates a multitude of colonial tropes and adapts them to the new generic context of science fiction in order to reinforce the superior status of white rational masculinity.

\section{End Notes}

1 AAA refers to mainstream games of a high production value that benefit from substantial marketing.

2 According to Marie-Laure Ryan, the text-actual world of a narrative represents what constitutes as being real in the fictional world (Possible Worlds 24-25). The storyworld is broader concept that encompasses not only what is real and actual in the narrative, but also alternative versions of the text-actual-world that may be envisaged by the characters called possible worlds ("Transmedial Storytelling and Transfictionality" 364). A player's engagement with a video game is not only concerned with the reality of the game world, but also with the dreams and aspirations of playable and non-playable characters.

3 A type of control that maps the player's actions of manipulating the controller onto the bodily movements of the playable character (Calleja 63).

\section{Works Cited}

\section{Ludography}

1. Atari. E.T. Extra-Terrestrial. Atari, 1982. or Halloween

2. Capcom. Resident Evil 4. Capcom, 2005.

3. Capcom. Resident Evil. Capcom, 1996.

4. EA Redwood Shores. Dead Space. Electronic Arts, 2008.

5. Human Head Studios. Prey. 2K Games, 2006.

6. Infogrames. Alone in the Dark. Infogrames, and I*Motion, 1992.

7. Irrational Games, and Looking Glass Studios. System Shock 2. Electronic Arts, 1999.

8. Konami Computer Entertainment Tokyo. Silent Hill. Konami, 1999. 
Carry the White Man's Burden to Outer Space - The Gamification of Colonization in Dead Space

9. Remedy Entertainment. Max Payne. Gathering of Developers, 2001.

10. Sony Interactive Entertainment Japan Studio. Forbidden Siren. Sony Computer Entertainment, 2003.

11. Wizard Video. Halloween. n.a., 1983.

12. Valve. Half-Life. Sierra Studios, 1998.

\section{Filmography}

1. Cameron, James. Aliens. 20th Century Fox, 1986.

2. Scott, Ridley. Alien. 20th Century Fox, 1979.

3. Kubrick, Stanley. 2001: A Space Odyssey. Metro-Goldwyn-Mayer, 1968.

4. Tarkovsky, Andrei. Solaris. Mosfilm, 1972.

\section{Secondary Bibliography}

Ashcroft, Bill, Gareth Griffiths, and Helen Tiffin, editors. Post-Colonial Studies. The Key Concepts. $2^{\text {nd }}$ ed. Routledge, 2007.

Calleja, Gordon. In-Game. From Immersion to Incorporation. MIT Press, 2011.

Egenfeldt, Simon, Jonas Heide Smith, and Susana Pajares Tosca. Understanding Video Games. The Essential Introduction. Routledge, 2008.

Erll, Astrid, and Ann Rigney. "Introduction: Cultural Memory and its Dynamics." Mediation, Remediation, and the Dynamics of Cultural Memory, edited by Astrid Erll and Ann Rigney, Walter de Gruyter, 2009.

Eskelinen, Markku. “The Gaming Situation.” Game Studies, Vol. 1, No. 1, 2012.

Jenkins, Henry. "Game Design as Narrative Architecture." First Person: New Media as Story, Juul, Jesper. "On Absent Carrot Sticks. The Level of Abstraction in Video Games" Storyworlds across Media: Toward a Media-Conscious Narratology, edited by Marie-Laure Ryan and JanNoël Thon, University of Nebraska Press, 2014, pp.

Perron, Bernard. "Survival Horror Games." Encyclopedia of Video Games: The Culture Technology, and Art of Gaming Volume 1, edited by Mark J.P. Wolf, Greenwood, 2012, pp. 636-638.

Ryan, Marie-Laure. "Transmedial Storytelling and Transfictionality." Poetics Today, Vol. 34, No. 3, pp. 362-88.

Ryan, Marie-Laure. Avatars of Story. University of Minnesota Press, 2006.

Ryan, Marie-Laure. Possible Worlds, Artificial Intelligence, and Narrative Theory.: Indiana University Press, 1991.

Wolf, Mark J. P. "Abstraction in the Video Games." The Video Game Theory Reader, edited by Mark J. P. Wolf and Bernard Perron, Routledge, 2003, pp. 47-66. 